\title{
Emprendeudores fracasados: individualización neoliberal en los discursos sobre el desempleo
}

\author{
Failed Entrepreneurs: Neoliberal Individualization \\ in the Discourses on Unemployment
}

ÁLVARO BRIALES

Universidad Complutense de Madrid y Fundación de Los Comunes

Artículo recibido: 28 junio 2016

Solicitud de revisión: 28 septiembre 2016

Artículo aceptado: 31 octubre 2016

Resumen

En este artículo sostenemos que el discurso del emprendimiento opera como un dispositivo de individualización de la relación salarial que oculta el fuerte contraste entre el plano ideal -autonomía, independencia subjetiva, éxito- y los obstáculos materiales reales - profundización del endeudamiento, alta proporción de fracaso, precarización-. Analizamos empíricamente dos casos: 1) el Foro de Activación para el Empleo de la Comunidad de Madrid que promueve lo que llamamos el narcisismo competitivo neoliberal; y 2) los contrastes entre el plano ideal y material en los discursos de personas en paro entrevistadas durante 2012 y 2013. Concluimos que las políticas de empleo que promocionan el emprendimiento no resuelven el problema del desempleo sino que, fundamentalmente, sirven para gobernar políticamente la precariedad masiva. Proponemos utilizar las categorías de emprendeudores y de emprendeudamiento para una mejor comprensión sociológica del discurso del emprendimiento.

Palabras clave: emprendedores, desempleo, deuda, neoliberalismo, discurso

\begin{abstract}
This article argues that the entrepreneurship discourse operates as an individualization apparatus of the wage relation which hides the strong contrast between the ideal level -autonomy, subjective independence, success- and the real material obstacles -deepening of debt, high failure rate, precarization-. Two cases are empirically analyzed: 1) The Activation for Employment Forum organized by Madrid regional government, which promotes what we call competitive neoliberal narcissism; and 2) the contrasts between the ideal level and the material level in the discourses of unemployed people who were interviewed in 2012 and 2013. It is concluded that employment policies that promote entrepreneurship do not solve the problem of unemployment but mainly serve to govern politically the massive precariousness. It is proposed to use the categories of emprendeudores and
\end{abstract}


emprendeudamiento [entrepreneurs + debt category] for a better sociological understanding of the entrepreneurship discourse.

Keywords: entrepreneurs, unemployment, debt, neoliberalism, discourse

\section{1. «EMPRENDEDORES»: CATEGORÍA CENTRAL DEL GOBIERNO DEL DESEMPLEO}

En 2013, España alcanzó el 27\% de desempleo y superó los seis millones de parados. Según los datos comparados del Banco Mundial sobre 206 países, ese año España era el quinto país del mundo con mayor tasa de desempleo, solo superado por Mauritania, Macedonia, Bosnia y Grecia. A pesar de este contexto, en nuestro país los discursos dominantes insistían más que nunca en presentar el desempleo como un hecho básicamente voluntario, lo cual permitía legitimar la progresiva retirada de los apoyos públicos a los desempleados: según la Encuesta de Población Activa, si a finales de 2009 medio millón de personas llevaban más de dos años buscando un empleo, cuatro años después, a finales de 2013 , esta cifra se multiplica por cinco, hasta los casi dos millones y medio.Tras una disminución permanente de la tasa de protección (Negueruela, 2014), dos de cada tres personas en paro no cobraban ningún tipo de prestación, y de quienes llevaban más de dos años buscando empleo, solo uno de cada cuatro recibía alguna ayuda pública. Paradójicamente, el tratamiento asistencialista y moralizador del desempleo ha ido aumentando a medida que los desempleados disponían de menos medios materiales: dentro de aquella minoría que cobraba alguna prestación, la proporción de aquellas de carácter asistencial -y mucha menor cuantía- aumentó del 39\% al 58\% entre 2008 y 2014 (Briales y López Calle, 2015: 96).

Con esta pequeña batería de datos, puede constatarse someramente la precarización y desprotección creciente de los desempleados. Ante esta situación, las políticas públicas no se han dirigido hacia la creación de empleo neto en cuanto tal ni a la protección de las capas más empobrecidas por la crisis. Podemos decir que la intervención política estatal se orientaba básicamente al gobierno del desempleo (Walters, 2000), o en otras palabras, a un management de los márgenes (Vosko, 2010) encaminado a contener la pobreza en su potencial conflictividad política por la vía de obligar materialmente a las capas más vulnerabilizadas a competir cada vez más entre sí por el acceso a los escasos trabajos, aumentando paulatinamente la presión sobre los salarios y las condiciones de vida. 
En términos generales, las explicaciones del desempleo por parte de la ortodoxia económica no pasaban por cuestionar el modelo productivo español, ni la división europea e internacional del trabajo, ni la desigualdad social, ni las relaciones de deuda, ni la polarización del reparto del tiempo de trabajo y su actual intensificación (Álvarez et al., 2014; Observatorio Metropolitano, 2010, 2011). Por el contrario, en las explicaciones oficiales se ha ido afianzando la presencia de una nublosa gama de categorías psicológicas e individualizantes: motivación, responsabilidad, resiliencia, talento, empleabilidad, activación, empoderamiento, flexiseguridad, y un largo etcétera de significantes vacíos que actualmente están «llenando» los debates públicos. Como es conocido, el análisis de los efectos de esta cultura de la psicologización de la relación salarial ha sido, en las últimas décadas, uno de los temas principales de la investigación social crítica (Sennett, 1998; Crespo et al., 2009; Fernández Rodríguez y Serrano Pascual, 2014).

En toda esta inflación discursiva, la categoría de emprendimiento ha sido uno de los lemas «estrella» que ha contribuido a situar el peso principal de las explicaciones del desempleo en la aparente poca cultura emprendedora de la población española y su innata y transhistórica tendencia a la vagancia (Alonso y Fernández Rodríguez, 2013). Así, es precisamente en el momento más grave de la crisis y de mayor conflictividad política, en 2013, cuando aparece una de las medidas más publicitadas aparentemente dirigida a la lucha contra el desempleo: la Ley 14/2013, "de apoyo a los emprendedores y su internacionalización». Tal ley puede considerarse como uno de los hitos que consolidan lo que parece ser la principal propuesta contra el desempleo de los gobiernos neoliberales: el emprendimiento.

Pero, ¿qué es un emprendedor? Según la citada Ley 14/2013: «Se consideran emprendedores aquellas personas, independientemente de su condición de persona física o jurídica, que desarrollen una actividad económica empresarial o profesional, en los términos establecidos en esta Ley» (Art. 3). Sin entrar en más detalles, la definición jurídica de partida caracteriza una vaga abstracción que puede incluir tanto una actividad «empresarial» como "profesional», es decir, se dirige a sintetizar en un solo continente los muy diversos contenidos que pueden incluirse bajo la categoría de «empresario» o de «trabajador». A pesar de sus connotaciones positivas, en los términos más generales la categoría de emprendimiento apunta a profundizar las principales líneas de las políticas de empleo neoliberales: la progresiva disolución de la mediación del contrato de trabajo y de la figura del trabajador asalariado dependiente, con la consiguiente individualización 
de los riesgos, la potencial eliminación de facto del reconocimiento estatal de la desigualdad de clase y, en último término, del ámbito de actuación del derecho laboral como derecho específico de los trabajadores, no de los individuos (Bilbao, 1997).

Como venía sucediendo desde los ochenta pero con más intensidad tras la crisis de 2008, esta colonización de los razonamientos economicistas asociados al emprendimiento está desbordando ampliamente la esfera del campo económico, del mercado laboral o de la empresa. Por ejemplo, en el caso español recientemente se están introduciendo explícitamente estas categorías en el currículum educativo ${ }^{1}$ o en programas de la televisión pública, ${ }^{2}$ y su hegemonía ha llegado a tal nivel que tampoco parece significativamente enfrentada en algunos espacios críticos o antineoliberales, ${ }^{3}$ entre otros posibles ejemplos. Paralelamente, se están creando y expandiendo nuevos dispositivos de saber asociados a la producción política del emprendedor. Tal y como ocurre con la racionalidad neoliberal (Laval y Dardot, 2010), ambiciosos proyectos como el Global Entrepreneurship Monitor (GEM) se presentan como científicos y neutrales bajo el aparente interés desinteresado de «medir», pero su marketing siempre va acompañado de posicionamientos explícitamente políticos como «aumentar la conciencia social acerca de la importancia del emprendimiento»y «sugerir políticas públicas que promuevan la actividad emprendedora» (GEM, 2015). En último término, si el emprendedor es concebido como la síntesis superadora de la división trabajador-empresario, sus formas de representación aspirarán a superar las concepciones de la estadística estatal del siglo xx que partía de la división estructural entre asalariados y empresarios. ${ }^{4}$

1 Por ejemplo, la idea del emprendimiento, junto con la del talento y la empleabilidad, recientemente ha sido incluida en el currículum educativo en secundaria, con la asignatura Iniciación a la Actividad Emprendedora y Empresarial, y aparece con frecuencia en la LOMCE (Ley Orgánica 8/2013, art. 24).

2 Otros ejemplos, entre muchos, pueden verse en los eventos organizados por el conocido portal Infojobs, o en la inversión en nuevos programas emitidos por la televisión pública estatal, RTVE: el programa semanal Emprende (http://www.rtve.es/television/emprende/) o el programa Aquí bay trabajo (http://aquihaytrabajo.rtve.es/).

3 Algunos ejemplos son: en Podemos, por ejemplo, se hizo un «banco de talentos» bajo la idea del emprendimiento «social»; en empresas de economía social y solidaria el discurso ha calado en buena medida también con el adjetivo «social» o «colectivo», y por ejemplo, la Universidad Mondragón -de la cooperativa homónima- tiene el Grado en Liderazgo Emprendedor e Innovación; el actual Ayuntamiento de Madrid gobernado por Ahora Madrid mantiene la Dirección General de Comercio y Emprendimiento, heredera de Madrid Emprende, creada en 2005 por el Partido Popular, y se subvencionan con dinero público proyectos como las Lanzaderas de Empleo y los Viveros que reproducen acríticamente las versiones más liberal-individualistas del discurso del emprendimiento.

4 Por ejemplo, lo que llaman la Tasa de Actividad Emprendedora (GEM, 2016) supone entrar en disputa con los conceptos estadísticos de la Población Activa. 
En resumen, la fuerza semántica de la figura del emprendedor concentra ambiguamente los aspectos positivos tanto de las categorías de «empresario» y «trabajador», y supera las figuras del autónomo - a menudo asociada al falso autónomo- del autoempleo, el trabajador por cuenta propia, el free-lance, etc., todas ellas semánticamente más asociadas al «trabajador»y bien diferenciadas de la categoría de "empresario» ya desde la Ley del Trabajo Autónomo. ${ }^{5} \mathrm{Y}$ al igual que, con todo ello, el estatuto del trabajador asalariado por cuenta ajena se está transformando semántica y materialmente, el significado de la búsqueda de empleo también está mutando. En ese sentido, la idea del «emprender» puede comprenderse como el siguiente paso de la llamada búsqueda «activa» de empleo. Si bien la esencia de la relación salarial no cambia, sí cambia su reconocimiento social. Según nuestra interpretación, tales cambios expresan el momento actual de las intervenciones políticas sobre la subjetividad del trabajo ${ }^{6}$ que, a pesar de ello, profundizan la condición fundante de la relación salarial: la obligación de acceder a las mercancías que son condición sine qua non de la reproducción vital a través del dinero obtenido por la venta del tiempo de trabajo.

En síntesis, un emprendedor es una figura más cargada positivamente y cercana al «empresario» que el autónomo, y condensa los aspectos positivos del «trabajador». Un emprendedor es pues un «empresario de sí mismo», un trabajador-empresario, un «hombre-empresa» (Laval y Dardot, 2010: 152). En definitiva, el emprendedor no es sino otro modo de denominar al mito del individuo liberal clásico, un sujeto autodeterminado sin lazos sociales de cuya voluntad depende su destino. Se trata de la reactualización de otra «robinsonada dieciochesca» de los economistas, en la vieja expresión de Marx (1857: I, 3-4), un intento de recuperar la abstracción de «un individuo aislado, fuera de la sociedad» que «no es menos absurda que la idea de un desarrollo del lenguaje sin individuos que vivan juntos y hablen entre sí». El «emprender» puede comprenderse como la actual ofensiva cultural para reintroducir el idealismo liberal abstracto en el significado del trabajo. ¿De qué modo se está actualizando y cuestionando este discur-

5 En 2007, se aprobaba la Ley del Estatuto del trabajo autónomo, ya que «el 94\% de los autónomos que realizan una actividad profesional o económica en el marco jurídico de empresa no tienen asalariados o solo tienen uno o dos.» (Ley 20/2007).

6 El movimiento de psicologización puede evidenciarse, simplemente, si se echa un vistazo en las actuales ofertas en un portal de internet como Infojobs: es común ver que un «requisito mínimo» de muchas ofertas de trabajo es la «Tolerancia al estrés» o la «Alta tolerancia a la frustración». El término «estrés» presenta lo que viene de la presión externa como si surgiera de la interioridad de las personas. Véase la investigación en curso de Carlos López Carrasco (2015). 
so en el caso de la crisis del empleo española? Esta es la pregunta que aborda nuestro artículo.

\section{EMPRENDEUDAMIENTO: EL TRABAJO DE OCULTAMIENTO DE LAS CONDICIONES SOCIALES DEL ÉXITO Y FRACASO}

En la situación de desempleo y precariedad masiva, la eficacia simbólica del discurso del emprendimiento se sostiene, entre otros aspectos, sobre la base de un trabajo de ocultamiento de las dificultades objetivas de emprender con éxito para la mayor parte de la población trabajadora.

Como la crisis de 2008 ha vuelto a evidenciar, la solvencia de una unidad económica no está bajo control de ningún individuo en cuanto tal, sino que depende de la relación de tal unidad económica respecto a unos flujos de capitales altamente volátiles y a una red productiva con enorme dependencia del crédito en el modelo productivo español. Con la gestión austeritaria de la crisis, la privatización de los beneficios por los grandes capitales y la socialización de las pérdidas en las poblaciones y empresas más desprotegidas, la deuda pública española ha alcanzado su récord histórico en 2016 superando el 100\% del PIB. Este endeudamiento estructural es el resultado de la financiarización previa (Alonso y Fernández Rodríguez, 2012): según los datos de la Contabilidad Nacional de España, la deuda de las familias pasó del 62\% de la renta disponible en 1995, hasta el $149 \%$ en 2007 , manteniéndose por encima del 140\% en los años posteriores (Observatorio Metropolitano, 2010: 251). La inversión del efecto rique$z a$ de la financiarización hizo que durante el periodo 2008-13 se cerraran cada día una media de 367 empresas con algún asalariado, de las cuales el 92\% tenían entre uno y cinco asalariados. Además, se dieron de baja un millón y medio de empresas sin asalariados. En términos comparativos, en ese periodo se dieron diariamente de baja 136 empresas más que en el periodo 2002-07. ${ }^{7}$ Lógicamente, la posibilidad real de abrir y mantener una empresa depende de la solvencia del endeudado, y el nivel de endeudamiento que se soporte no depende de meras actitudes individuales sino de

7 Según los datos de Movimientos del Directorio Central de Empresas del INE, en el periodo 2008-13 se han dado de baja 804.615 empresas con al menos un asalariado, y 1.482.496 empresas sin asalariados. Eso significa que en esos seis años cerraron de media 367 empresas por día con algún asalariado. En comparación con los seis años anteriores (2002-2007), las bajas de empresas con algún asalariado fue de 528.799, o lo que es lo mismo, 241 empresas al día. En otros datos del Ministerio de Empleo, en diciembre de 2013 había 1.158.336 empresas inscritas en la Seguridad Social, lo que significa unas 247.600 empresas menos que en 2007. 
su poder económico relativo en un contexto en el que la crisis de las clases medias parece no tener solución a medio plazo (Observatorio Metropolitano, 2010, 2011). Según el propio Global Entrepreneurship Monitor (2016: 74-75), lo que llaman la Tasa de Actividad Emprendedora es entre tres y cuatro veces superior en el tercio de la población con más renta y estudios, en comparación con el tercio inferior. En síntesis, mientras la única propuesta de solución al desempleo era "emprender», la posibilidad real de abrir una empresa estaba fundamentalmente limitada: del conjunto de la población trabajadora, el 25\% estaba en desempleo, mientras el 50\% cobraba menos de mil euros (entre estos, la mayoría cobrando menos del Salario Mínimo). ${ }^{8}$

Con estos datos generales, puede deducirse fácilmente que lo que explica el mejor o peor acople a la crisis no son las capacidades o actitudes individuales ni tampoco el hecho de pertenecer a la categoría de «empresario». Lo determinante es tener la posición de poder social y económico dentro del tejido productivo-financiero que se define relacionalmente en función de la capacidad de sostenerse frente a los vaivenes relativamente impredecibles de los mercados. O dicho metafóricamente, ha sido el volumen de los «tsunamis» que han venido lo que ha determinado cuántos sectores, cuántas empresas y cuántos trabajadores se han hundido, y cuántos han podido mantenerse o reposicionarse tras los reajustes del conjunto de las redes productivas del precario modelo postburbuja inmobiliaria. Por tanto, el emprendedor exitoso no es exitoso por su posición subjetiva - «yo puedo», «quien la sigue la consigue», etc. - sino por su posición de poder.

Por tanto, en la medida en que opere con mayor o menor eficacia el ocultamiento de las condiciones sociales del éxito económico, tomará mayor o menor sentido la ideología de que con el mero esfuerzo constante uno podrá crear una empresa rentable y mantenerse en condiciones de vida dignas y estables. En términos de Pierre Bourdieu, el emprendimiento depende de las luchas competitivas por el capital cultural, capital social y capital económico que determinen el nivel de mayor o menor seguridad relativa, es decir, la mayor o menor solvencia frente al endeudamiento estructural que antes señalábamos. En este sentido, nos es útil hablar de emprendeudores (Moruno, 2015: 147-164) y de emprendeudamiento para

8 Siguiendo la crítica a la metodología de la Encuesta de Estructura Salarial (BSE, 2014a) -que, entre otros problemas, realiza el cómputo excluyendo el Régimen agrario y el Régimen de empleo de hogar- en 2012, los trabajadores pobres - que cobran menos del Salario Mínimo Interprofesionalserían un tercio del total, y la mitad cobraría menos de mil euros; además, ha disminuido el salario medio real hasta un mínimo histórico en 2013 - 18.504 euros-, siendo el más bajo de los últimos 22 años en euros constantes (BSE, 2014b). 
señalar la relación intrínseca entre emprendimiento y endeudamiento. La positividad del emprendimiento abstracto que se lanza desde los discursos dominantes tiene en realidad como pesada condición una profundización de las relaciones de deuda: además de los datos ya señalados, siete de cada diez emprendedores dependen de financiación externa. ${ }^{9}$ Como ha sido difundido en los últimos años en el contexto europeo - pero que ya era conocido sobre todo desde la enorme deuda externa de los países latinoamericanos desde los ochenta-, la deuda es uno de los mecanismos centrales de disciplinamiento neoliberal, e imbrica niveles muy diferentes de gobierno: desde las imposiciones a la soberanía de los Estados desde la Troika en el nivel más alto, hasta el sentimiento íntimo de culpabilidad por no poder devolver la deuda, pasando por la regulación estatal del crédito o las diferentes formas administrativas y penales de castigar a las poblaciones endeudadas. La dimensión de la subjetividad endeudada es la que vamos a explorar más en este artículo. El endeudamiento como posibilidad de «aumentar indefinidamente» el «capital humano» aparece como una de las garantías centrales del gobierno del desempleo. Como señalan Laval y Dardot:

el endeudamiento crónico es productor de subjetividad y acaba convirtiéndose en un verdadero "modo de vida» [...] Se trata, de hecho, de producir una relación del sujeto individual consigo mismo que sea homóloga a la relación del capital consigo mismo: una relación, precisamente, del sujeto con él mismo como "capital humano» que debe aumentar indefinidamente, o sea, un valor que hay que incrementar cada vez más (Laval y Dardot, 2010:21).

Si se sigue hasta aquí nuestro argumento, nos parece de un interés sociológico central indagar las contradicciones existentes en los desempleados españoles respecto al emprendimiento. Como hemos señalado, existe por un lado una serie de discursos ideales del emprendimiento que afirman que el éxito y el fracaso dependen de variables psicológico-individuales, ${ }^{10}$ y por otro lado, todo un conjunto de obstáculos materiales que dificultan el éxito y llevan al fracaso social de las personas en desempleo. Con este análisis cualitativo queremos avanzar en la identificación de los ejes del difuso discurso del emprendimiento, sus efectos de individualización y de ocultamiento de lo social, sus fronteras semánticas respecto a la búsqueda

9 Según los datos del Global Entrepreneurship Monitor de 2014 (GEM, 2016: 76).

10 En la reciente investigación del proyecto TRACuvi, esta fuerza individualizadora se ha visto claramente en diferentes discursos y prácticas de diferentes grupos sociales (Callejo, 2015; Santiago, 2015), en el que la libertad de elegir es, más bien, la obligación de elegir (Laval y Dardot, 2010: 225). 
de empleo, y evaluar hasta qué punto tales discursos están teniendo una mayor o menor eficacia simbólica en quienes materialmente viven «el gran tabú moderno» del fracaso (Sennet, 1998: 124-142). Queremos comprender en qué medida está siendo eficaz el trabajo de ocultamiento de las condiciones del éxito y el fracaso económico, qué contradicciones implica, y con qué argumentos ese sentido común podría estar siendo cuestionado.

\subsection{Metodología y datos}

Para el análisis del discurso ideal, hemos escogido un caso significativo: el Foro de Activación para el Empleo organizado por la Comunidad de Madrid en 2014. Como es conocido, la Comunidad de Madrid, con Esperanza Aguirre a la cabeza en aquel momento, ha sido uno de los principales laboratorios de las políticas neoliberales en España (Observatorio Metropolitano, 2012). Este caso nos mostrará cómo el discurso de la búsqueda activa de empleo está mutando de manera que cada vez se hibrida más con el discurso del emprendimiento, y nos señala la «punta de lanza», la vanguardia discursiva, por así decirlo, hacia donde pueden apuntar los discursos de las futuras políticas de empleo. No es necesariamente representativo en términos distributivos, pero sí podría serlo en términos estructurales.

Para el análisis de los obstáculos materiales a la eficacia del discurso del emprendimiento, los datos cualitativos que usamos han sido obtenidos en el marco de un proyecto de investigación sobre la vida cotidiana en España (Prieto, 2015), y dentro de este, a partir de una investigación sobre el tiempo del desempleo durante la crisis de 2007-13 (Briales, 2016). Los datos cualitativos se obtuvieron de una base de seis grupos de discusión y 28 entrevistas semiestructuradas realizadas en 2012 y 2013 a personas que están o han estado intermitentemente en paro. Por la extensión de este artículo, hemos escogido datos de tres grupos de discusión y siete entrevistas (ver Anexo metodológico). Se seleccionaron condiciones sociales heterogéneas, pero en general se acotó la muestra a familias heterosexuales con hijos. Se preguntó a las personas por los usos de su tiempo en la vida cotidiana, y los contrastes vividos en el paro respecto a la situación de empleo. Dada la presencia masiva del discurso del emprendimiento en aquel momento, sus categorías típicas surgieron de manera natural en las conversaciones, lo que nos proporciona la base del análisis que presentamos. ${ }^{11}$

11 Para más detalles metodológicos, véase Briales (2016: 121-131). 


\section{EL EMPRENDIMIENTO EN LOS DISCURSOS SOBRE EL DESEMPLEO}

3.1. De la búsqueda «activa» de empleo al emprendimiento: un caso de promoción del narcisismo competitivo como política de empleo

Dentro de los múltiples tópicos de los discursos asociados al emprendimiento, analizamos a continuación un caso, entre otros posibles, que ilustra el sentido individualizador del discurso del emprendimiento y sus categorías asociadas. Como veremos, aunque este foro aparece asociado principalmente a la búsqueda de empleo, puede verse cómo el tipo de sujeto que construye está difuminado: entre el buscador "activo» de un empleo asalariado y el sujeto emprendedor ya no hay fronteras claras, pues ambas figuras tenderían a percibir su actividad laboral como una actividad individualizada, en la que cada vez tiene más peso subjetivo lo que denominaremos el narcisismo competitivo neoliberal. En la siguiente tabla pueden verse los títulos de los ejes temáticos y los talleres de este Foro.

Tabla 1.

Foro de Activación para el Empleo (Comunidad de Madrid, 2014)*

\section{MUÉSTRATE}

- Tú eres tu carta de presentación.

- Cómo realizar una candidatura espontánea para buscar trabajo.

- Compite a través del cv.

- Cómo hacer un cv 2.0.

\section{ENTRÉNATE}

- Energía positiva ante los retos.

- Estrategia y automotivación: Historia de una medalla 100.

- Factores clave para el éxito en el deporte y el empleo.

- Alcanza tus metas. Optimiza tu cv.

\section{DIFERÉNCIATE}

- No hay una 2. ${ }^{\text {a }}$ oportunidad para causar una $1 .^{a}$ impresión.

- Tú, tu marca personal.

INNOVA

- Búsqueda de empleo creativa... Imagina que...

- Sí ¡Te encontré a través de tu web personal!

- ¿Cómo puedo utilizar las redes sociales en la búsqueda de empleo?

- ¿Cómo sacar el máximo partido a Linkedln? 
PLANIFICA

- Cómo enfrentarse a un proceso de selección internacional.

- ¿Cómo afrontar los test psicotécnicos y las pruebas profesionales de la mejor manera?

- ¿Cómo puedo planificar una entrevista de selección de personal?

- Gestiona tu tiempo en la búsqueda de trabajo.

$-$

PREPÁRATE

- Entrevista de trabajo: «El casting de tu futuro».

- Miedo escénico: seguridad y confianza.

- El trabajo efímero.

- Diseña tu carrera profesional.

\section{RECÍCLATE}

- ¿Qué buscan las empresas? ¿Méritos, idiomas, simpatía, empatía...?

- Hay empleo. No hay trabajo.

- Cómo desarrollar habilidades y competencias para el trabajo.

- ¿Estás preparado/a para las preguntas de las nuevas entrevistas de selección?

- Afronta nuevos retos ¿Necesitas un cambio?

\section{CONÉCTATE}

- Conéctate con tu talento.

- ¿Cómo tengo que hacer una entrevista por videoconferencia?

- ¿Qué es el Networking? Aprende a gestionar tus redes de contactos para la búsqueda de empleo.

- Gestiona adecuadamente tu posicionamiento en internet.

$-$

CREA

- Yo soy emprendedor.

- ¡Eureka! Tengo una idea de negocio.

- La franquicia como fórmula de autoempleo

ENCUENTRA TU VOCACIÓN

- Trabajar «turisteando». (Pasión por el turismo y búsqueda de empleo).

* En mayúscula, los ejes temáticos. Dentro de cada eje, los títulos de algunos talleres organizados.

Hemos tomado este ejemplo para ilustrar cómo una parte importante de la estrategia de las políticas de empleo no se basa en crear empleo sino en intensificar la competencia social mediante la promoción repetitiva de toda una gama de categorías psicologizantes e individualizadoras. Probablemente, el perfil de los actuales reproductores de estas categorías se reduce a jóvenes en paro de clases medias y altas, alta cualificación y altas aspiraciones laborales, puesto que para la mayor parte de los sujetos de nuestra investigación, estas categorías no están en los discursos con una presencia masiva. Precisamente por ello, nos hablan del tipo de sentido común que las actuales políticas de empleo pretenden difundir para una futura subjetividad laboral. Y que no estén aún difundidas en todo el conjunto social no significa que su proliferación no esté ya teniendo efectos socioculturales importantes. 
En este marco de comprensión del desempleo, una vía para fomentar la competencia generalizada de individuos consiste en estimular la producción de sujetos - en sentido foucaultiano- implicados ideológica y afectivamente en la afirmación de su narcisismo, omitiendo así la posibilidad de percibir el desempleo como un hecho propiamente social. Como vemos, las categorías intentan interpelar y «seducir» a los parados potencialmente emprendeudores para que busquen las soluciones a su desempleo en un diálogo consigo mismos: «muéstrate», «entrénate», "planifica», «prepárate», «recíclate», «diferénciate», «innova», «conéctate», «crea», «encuentra tu vocación». Tales categorías evitan mencionar algún tipo de colectividad sino que apelan al «yo». ¿Quién sería el sujeto que enuncia ese «conéctate», «entrénate», etc.? Aparece tanto como una orden enunciada desde el exterior, pero al mismo tiempo es una orden que se presenta como interna: dicho en términos psicoanalíticos, un superyo imponiéndose sobre el yo, es decir, un nuevo tipo de moralidad que está en proceso de interiorización, y que por tanto produce una fuerte ambivalencia: estimulan el deseo de emprender mientras que «emprender» es cada vez más una obligación objetiva dentro del desempleo masivo y la escasez de puestos de trabajo.

Los títulos de los talleres del Foro enmarcan el sentido de las estrategias del desempleado como las de un sujeto solo frente al mundo. El sujeto que responde a estas interpelaciones tenderá a interpretar su destino como resultado de sus acciones individuales, y borra la existencia de la dinámica social que es imposible dominar individualmente: se trataría de una forma especialmente extrema de introducir la ilusión biográfica (Bourdieu, 1989) en la percepción de las continuidades y discontinuidades de la trayectoria social de un sujeto. En esa narración individualista, este sujeto omnipotente rompe los lazos de solidaridad social para enfocar todas sus prácticas a «autoayudarse», a solidarizarse exclusivamente consigo mismo, si puede decirse así. Por ello, puede entenderse que la función de este exceso de narcisismo consiste en compensar el déficit de lazos afectivos hacia el exterior que produce la competencia de todos contra todos, negar la interdependencia realmente existente, y así, a medida que el sujeto incremente su implicación afectiva con su ideal de trabajador autosuficiente (Pérez Orozco, 2014), tendrá más energía para prolongar su inversión de tiempo en el trabajo: «seguridad», «confianza», «automotivación», «energía positiva», «mi talento», «mi marca personal», «mi futuro», «mi conexión conmigo mismo», «mis retos», «mi posicionamiento en internet» son formas de un plus de narcisización que permiten al parado afrontar, al menos contingentemente, la creciente presión social en condiciones de soledad e 
individualización. Es decir, si la obligación objetiva de competir por el acceso al dinero acrecienta la coacción sobre el sujeto, ¿cómo hacer que esta coacción se vivencie como la afirmación de la propia singularidad libre? Estos discursos tienden a producir sujetos cuyo ideal del yo se realiza en el acto de venderse, lo que resignifica el acto que lo hace objeto en el acto que lo afirma como sujeto. Como es evidente, este proceso histórico no es nuevo sino que, más bien, encuentra ahora sus últimas formas.

Así, el narcisismo competitivo puede entenderse como una de las vías para promover un tipo específico de subjetivación, mediante la cual la intensificación del ideal del sujeto autosuficiente aumenta la probabilidad de que un emprendeudor se sienta menos dominado a medida que está más dominado. Desde la lógica más individualista, la socialización en el ideal narcisista se transforma en una ventaja competitiva para trabajar a corto plazo, ya que impulsa máximamente al sujeto a invertir todo su tiempo en el proyecto de emprendeudamiento. Bajo esta lógica, un factor más que promueve el «espíritu competitivo» de los emprendeudores es su plus de implicación afectiva en la venta exitosa de sí mismos, independientemente de si el resto de la población vive dignamente o no, e independientemente de si la tasa de paro es del $1 \%$ o del $30 \%$, por decirlo en términos llanos. En la interesante forma de expresarlo de Berardi:

una consecuencia de la deserotización de la vida cotidiana es la inversión de deseo en el trabajo, que se convierte en el único lugar de confirmación narcisista para una individualidad acostumbrada a concebir al otro según las reglas de la competencia, es decir, como un peligro, como un empobrecimiento, como un límite, más que como una experiencia, un placer, una forma de enriquecimiento (Berardi, 2003: 65).

Por tanto, la condición narcisista del emprendedor aumenta en el corto plazo las probabilidades de que el emprendeudor acceda al dinero, ya que acrecienta su competitividad; si bien, si el proyecto de emprendeudamiento no resulta exitoso - lo que ocurre en la mayoría de casos-, el plus de soledad y potencial depresión melancólica será máximo, no solo por la pobreza material, sino también por la ruptura de otros lazos sociales de solidaridad y la imposibilidad de no autoatribuirse el fracaso propia del sujeto que anhela su autosuficiencia (Briales, 2016:330-45).

$\mathrm{Y}$ antes de pasar a los discursos de los desempleados, como se ve, cabe destacar la clara borrosidad entre el sentido de la búsqueda de trabajo, como búsqueda de un puesto de trabajo, y el emprendimiento en el sentido de constituir una actividad económica como «autónomo» $\mathrm{o}$ "empresario». Del sujeto de la búsqueda «activa» de empleo al sujeto emprendedor 
ya hay muy poca distancia semántica, lo cual refleja la disolución progresiva de la figura del trabajador asalariado con derechos que compensaría la desigualdad estructural públicamente reconocida.

3.2. E1 emprendimiento en los discursos de personas en paro: entre el discurso ideal y los obstáculos materiales

\section{Motivos ideales del emprendimiento}

A continuación, hemos seleccionado algunos fragmentos de discursos de desempleados en los que muy resumidamente se señalan los motivos que animarían a emprender y, de ese modo, renunciar a la búsqueda de un empleo por cuenta ajena.

muchas veces estamos... como veo, por ejemplo, que no encuentro trabajo, y él está hasta aquí de estar siempre con jefes que no merecen la pena, y que le amargan la vida, pues siempre pensamos en montar una empresa (Daniel).

Sí, porque tú eres tu propio jefe (Antonio).

Entonces me quiero emprender porque esa es la motivación que tengo ahora, que no quiero volver a una oficina de ocho a tres (Precarias).

Sí me gustaría, hombre, claro. Trabajar por uno mismo. Aunque sea más duro y demás (José).

Para mí ahora lo más importante es poder emprenderme en lo que yo realmente siento ahora, sea de futuro, no sea, funcione, no funcione. [...] y desde luego que el tener una hija también me lleva a esto porque así soy yo flexible con mi maternidad y con el trabajo y puedo ir yo adaptándolo, siendo yo autónoma puedo ir yo adaptándolo a mis necesidades familiares ¿no? (Precarias).

$[\ldots]$ yo en mi casa como a mí me da la gana, ¿no? (Parados CD).

Como vemos, algunos de estos motivos ideales son: 1) la ausencia de «jefes» $\mathrm{o}$ «ser tu propio jefe»; 2) el rechazo a la rutina de un trabajo repetitivo - «oficina de 8 a 3»-;3) el deseo de trabajar «por uno mismo», asociado a la independencia; 4) la flexibilidad con la «maternidad»y las «necesidades familiares», es decir, la posibilidad de que el emprendimiento permita una mejor conciliación de la vida laboral y familiar, lo que es especialmente deseado por las mujeres; 5) la posibilidad de trabajar desde casa como un espacio de mayor comodidad.

Desde la óptica de estos motivos, el emprendimiento sería una solución no solo al desempleo, sino a las malas condiciones de trabajo. Si se pudiera 
emprender exitosamente, podría evitarse el mando de un jefe, la rigidez de los horarios aburridos y repetitivos que no permiten conciliar, y también podría conseguirse una mayor sensación de independencia, de modo que uno se pudiera autoatribuir tanto salarial como simbólicamente los posibles éxitos. En síntesis, el motivo más fuerte del emprendimiento es la búsqueda de una mayor autonomía en la actividad laboral en particular y en el tiempo de vida en general. ¿Qué obstáculos materiales aparecen en estos mismos parados o en otros que han querido abandonar su relación salarial tradicional para emprender?

\section{Endeudamiento y clase: motivos materiales del "desemprendimiento»}

Como señalábamos anteriormente, lo que hoy se presenta como el gran motivo ideal de la independencia parecería un corolario necesario de la propia categoría de emprendedor -o de autónomo- y del estatus reconocido a tal categoría. Sin embargo, la categoría formal de autónomo -al igual que ocurre a menudo con la de empresario- no dice nada en sí misma si no señala cuál es la posición real en la red de relaciones que definen la propia posición (Rolle, 2003). Veámoslo con algunos casos en relación al endeudamiento que aparece como condición del emprendimiento:

Dejé eso y dije: bueno, voy a poner yo un negocio de emprendedores, y abro un negocio, y a ver si salgo adelante.Ya me cotizo yo, ya pago como autónomo.Y al final tuve que dejarlo porque en casa no entraba dinero. Deudas por todos los lados, ¡hasta aquí, hasta arriba! Y entonces me puse a buscar trabajo (Matilde).

Es que no te da un duro nadie. Yo he estado presentando un proyecto ahí en la Cámara de Comercio, con la Aval Madrid, con el otro, con tal... «Sí, sí me parece cojonudo, lo veo viable. Pero si quieres que te demos el dinero, tienes que avalar con el pisito, y con todo lo que tengas.» [...] a mí la Cámara de Comercio me manda una carta diciendo: «Nos parece cojonudo, has estado demasiado pesimista».Y llegas al banco: «A ver, ¿qué tienes tú?». «Pues yo no tengo nada. Tengo una casa hipotecada. Pero tengo una idea cojonuda que podría funcionar». «Pues dile a tu madre que si te deja el dinero (Precarios).

Es lo que había pensado, abrirme mi propio negocio. Estuve a punto. Pero si me sale mal, embargo a mi madre más. Porque si lo hago, me tenía que ayudar mi madre con un aval (Antonio).

La verdad ahora los que están basando las políticas en emprender, el que te inventes tu propia empresa. He visto el otro día en un banco un cartel así de grande: Emprendedores: 18 mil millones. Sí, sí, si me va a colocar, será tu madre (Precarios).

Como ya dijimos, en la mayoría de casos el emprendimiento implica realmente condicionar la independencia ideal a la dependencia real de la 
deuda: es por ello que, nuevamente, cabe hablar de emprendeudamiento. Podrá ser emprendedor no quien tenga más deseo de independencia ni mejores ideas para la economía o la sociedad, sino sobre todo quien tenga más capacidad real de endeudarse: como señalan diferentes emprendeudores fracasados y/o frustrados, por ejemplo, con sus ahorros, con el aval de sus propiedades, o con las propiedades o dinero de su familia. La contrapartida real es, entonces, hipotecar el presente hacia un tiempo futuro: mientras no se solvente la deuda, siempre habrá algún riesgo de embargo, no ya de las propiedades individuales solamente, sino como es común, de las propiedades familiares y, especialmente, poniendo en riesgo la principal fuente de seguridad vital: la vivienda. Si el endeudamiento se materializa, tal mecanismo favorecerá el grado óptimo de presión constante sobre el sujeto emprendeudor, así como su individualización máxima, haciendo que la competencia externa se transforme, o bien en una mayor autorregulación de la propia actividad, o bien en un ulterior desborde del sujeto que derivará en depresión, precarización o exclusión social.Al menos en el corto plazo, en tanto que la deuda debe ser resuelta individualmente, para el emprendeudor será funcional enfocarse hacia ese narcisismo competitivo que analizábamos antes.

En consecuencia, en el caso de quien para emprender tiene que dedicar un tiempo prolongado al ahorro para realizar la inversión inicial, este tiempo de ahorro favorece el disciplinamiento y el uso intenso del tiempo. De ese modo, el gobierno efectivo de los emprendeudores no opera únicamente durante el tiempo de devolución de sus deudas, sino también durante el momento previo de ahorro o inversión inicial. Los discursos deben insistir entonces en que tal periodo de ahorro sea visto como un sacrificio contingente que, en un futuro, dará acceso a la deseada independencia. De ese modo, el endeudamiento opera como un dispositivo de individualización que oculta las dependencias objetivas mientras hace aparecer al emprendeudor como independiente. En consecuencia, la condición permanente del emprendimiento es la aceptación voluntaria de la dependencia objetiva, que se ratifica con la solicitud «voluntaria» del crédito, de la hipoteca o del préstamo, y que de ese modo establece las condiciones futuras para materializar nuevamente los discursos del «has vivido por encima de tus posibilidades», «no leíste la letra pequeña», o «por qué pediste un crédito si no lo podías pagar», etc.

Respecto a otro de los motivos ideales que veíamos, el de la ausencia de jefes, es contrastado así por un parado que fue free-lance: "Por esto es que yo me hice autónomo, pero al final era un free-lance, que tenía también que 
soportar una pila de directivos, igual. Que si esto sí, que si esto no, que si yo no voy con esto, se cae, tienes que pagar» (Parados $\mathrm{CD}$ ).

Como se ve, la ausencia de jefes formales no implica la ausencia de jefes reales, de cuyas decisiones se depende tanto para cobrar o no cobrar como para tener carga de trabajo o no tenerla. En la cita se distingue entre «autónomo», que sería una figura más ideal de independencia, y el free-lance, que sería una figura materialmente más dependiente. Cuando el parado dice «al final era un free-lance» se refiere al contraste entre lo que creía que iba a ser en un principio y lo que después fue.

Otro motivo ideal del emprendimiento, que lo concibe como una estrategia para poder pasar más tiempo en casa y tener más posibilidades de conciliación de la vida laboral y familiar, es visto así por estos parados:

no, no, yo en mi casa como a mí me da la gana, ¿no? Por lo tanto, si tú ya te llevas tu trabajo a tu casa, ya inclusive ni te vas a vestir como tú quieras, porque tienes la empresa, en el caso mío que era autónomo, free-lance, lo tengo en casa [...] Pero era un esclavo, era un esclavo de mi trabajo (Parados $\mathrm{CD}$ ).

Yo tengo un amigo que ahora trabaja en casa.Trabaja en una empresa de informática, pero trabaja en casa porque la empresa está jodida; y para reducir gastos de local, de luz, de calefacción, de aire acondicionado, tienen que trabajar en casa. La idea es buena, pero el motivo es así. Cómo puede ser que, por reducir gastos, no me parece que sea el motivo.Al final, trabajas en tu casa, y gastas tu calefacción, tu luz, tu aire, tus instalaciones (Precarios).

En el primer caso, más que como una flexibilidad positiva, el parado vive su situación de free-lance como una invasión del trabajo en el espacio privado. De ese modo, lo que idealmente aparecía como la libertad de trabajar en casa, finalmente es una coacción sobre su espacio de libertad y privacidad. Según se afirma, ser formalmente «autónomo» no conllevaba necesariamente autonomía, sino la condición de ser un «esclavo» del trabajo.Además, la casa se convierte en el espacio físico del trabajo, con la transferencia y privatización de gastos que ello conlleva, como se veía en la segunda cita.

Otro tema significativo que señala el contraste entre el discurso ideal y los obstáculos materiales es el de la ineficacia de las administraciones públicas. Por ejemplo, así se expresaba un parado que fracasó en el intento de asesorarse en los publicitados programas de ayuda al emprendedor ofrecidos por las administraciones públicas:

Y pensé: a ver si me pongo de autónomo. Es que tengo unos conocidos que han vivido en Ecuador, entonces vi la posibilidad de importar un producto de allí. Y entonces fui a Emprendedores de la Comunidad de Madrid, a Emprendedores del Ayuntamiento de Madrid, al Ministerio de no sé qué... A las tres administraciones fui: «Sí, porque tenemos una 
oficina para los Emprendedores». «Vale, bien.» «Sí, tú dame el proyecto, hazme un estudio de mercado». Sí, vale, esto ya lo he oído mil veces: definir el producto, hacer un estudio de mercado, estudiar la competencia... fenomenal, todo muy bonito visto en un papel. Pero esto, ¿cómo lo saco de aduana? El producto ese, al ser un producto natural, ¿qué trabas tiene, qué impuestos tiene...? "Infórmame». «Pues no tengo ni idea.Tú, dame los papeles. O si no, mejor vete al Ministerio de Agricultura». ¡Se echaron la pelota los tres! Hay tres administraciones cobrando para decir que ayudan al Emprendedor (Precarios).

Como es conocido, las políticas de empleo actuales han puesto muchos de sus recursos en la promoción del emprendimiento, con el objetivo de intentar demostrar su apoyo a proyectos empresariales incipientes. Aunque el precario de esta cita había concretado la disposición abstracta de emprender en un posible negocio de importación, en la realidad debe disponer de un capital cultural acumulado previamente: saber hacer un buen estudio de mercado, saber acceder a la información que permite organizar una empresa en un sector específico, etc. El precario potencialmente emprendeudor señala, efectivamente, que es «muy bonito visto en papel». El capital cultural (y social) necesario para crear empresas realmente solventes se adquiere, fundamentalmente, en las escuelas de negocios y en los programas de educación privada, de alto coste e inaccesibles para la mayor parte de la población, con los cuales ninguna administración pública está en condiciones de competir en mínimas condiciones de igualdad, y que en todo caso se dedican a proveer de pequeños apoyos a pequeñas empresas que, en su mayoría, estarán básicamente desprotegidas en caso de crisis. Del mismo modo, son las mismas clases acomodadas que pueden acceder a tales programas las que, por los mismos motivos, tendrán mayor capacidad para endeudarse y ser solventes a futuro.

\section{Entre la independencia subjetiva y la dependencia objetiva}

Yo no exijo un trabajo, exijo dejar de tener la sensación de trabajar

(MEJIDE, 2015).

Vistos los anteriores ejemplos, podemos decir que el proceso de individualización de la relación salarial está operando una importante transformación en la percepción del trabajo, al resignificarlo como «autonomía» o «emprendimiento» cuando realmente constituye la misma relación: la obligación objetiva de vender el tiempo de vida por dinero en condiciones de 
potencial insuficiencia material. En este sentido, las nuevas regulaciones jurídicas y los discursos individualizadores están teniendo efectos muy importantes en los que el tiempo de trabajo aparece como actividad libre e individual cuando materialmente está crecientemente sometido a la presión competitiva general.

En el fondo de todo este problema está la percepción del sentido del tiempo de trabajo.Veamos un pequeño ejemplo más: «Y el tiempo que siento que estoy dedicando, aunque sea laboral, pero el tiempo que estoy dedicando para mi proyecto también es un tiempo para mí.» (Precarias). Esta parada potencialmente emprendeudora concibe ese tiempo invertido en un proyecto laboral como tiempo propio o "para mí» (Callejo, 2015). ¿Qué significa esa expresión? Lo que nos interesa de este tipo de vivencia del tiempo es que está alterando el sentido del desempleo y del trabajo: de ser un tiempo percibido como una obligación para poder trabajar o un tiempo no-libre, pasa a ser un tiempo "propio» voluntariamente utilizado. Su sentido es ambivalente, porque hibrida dos tiempos antagónicos. De esa manera, el emprendimiento y sus significados asociados se caracterizan por invisibilizar la contradicción del sujeto que se cree autosuficiente mientras más dependiente es; es decir, como hemos visto, hace pasar el tiempo invertido en intentar vender la propia fuerza de trabajo como un tiempo libremente elegido.

A continuación, tenemos otra muestra significativa de cómo la aparente independencia subjetiva de Hilario - un parado exautónomo- se demuestra falsa en cuanto emerge la dependencia objetiva:

\begin{abstract}
Analizas la situación y dices «joder, si pago 250 euros más a la Seguridad Social y la Seguridad Social ahora no me garantiza a mí un futuro. Pues yo cojo estos 250 euros y lo pongo en un plan de pensiones. [...] Yo como autónomo pagaba mi recibo como autónomo, sabiendo que no iba a tener paro y otros 200 euros me hice un plan de pensiones. ¿Qué ocurrió? [...] Yo sí sabía a ciencia cierta que no iba a tener paro, pero por eso hice yo un plan de pensiones para esas cosas, pensando en el futuro. Pero claro, vinieron mal dadas y tuve que echar mano de ese dinero. [...] Punto.Y tuve que echar mano de ello por necesidades, y no tengo nada (Hilario).
\end{abstract}

Descubrimos con esta cita que la idea del emprendimiento puede conllevar también una transformación en la percepción del uso del dinero. Con el estatuto de autónomo, a Hilario se le abría una posibilidad que antes no tenía: la de decidir el destino de su cotización entre la Seguridad Social o un plan de pensiones privado. Esta «libertad de elegir» cómo uno planea su protección futura, genera la percepción de una mayor capacidad en el uso del dinero, que parece un objeto controlado por las decisiones del emprendeudor. Pero cuando emerge la crisis, quien parecía el agente - Hi- 
lario- se convierte en paciente del dinero. La decisión de Hilario de invertir "pensando en el futuro» de un plan de pensiones privado, le hace sentirse responsable de su dinero, mientras al mismo tiempo desresponsabiliza al Estado de su protección futura. El cálculo de costes y beneficios que el estatuto de autónomo permite, lleva a Hilario a creer que controla individualmente su futuro cuando decide invertir en el plan de pensiones más rentable - el privado-, pero socialmente, ese acto le encadena con más intensidad a los vaivenes del dinero, lo cual le impide controlar su futuro. Es así como el poder del dinero emerge con más violencia cuando la crisis le obliga a retirar todos los ahorros de su plan de pensiones, lo cual le deja sin derecho a prestación ni pensión digna tras cuarenta años trabajando: «no tengo nada». Como fue él quien creyó decidir libremente lo que hacer con su dinero, no puede ahora culpar a nadie más que al azar de la crisis o a sí mismo. Al haber sido formalmente "autónomo», su pobreza actual se presenta como el resultado de las decisiones erróneas del pasado, y no como el resultado de una «libertad de elegir» que, en el marco de la neoliberalización, le ha dejado desprotegido tras toda su vida trabajando.

Mientras que hemos visto cómo Hilario naturalizaba su situación gracias a la percepción de su condición de autónomo, otros trabajadores asalariados en paro, como Jenaro o Andrés, tienen la sensación de haber fracasado por no haber sido autónomos o emprendedores:

La culpa es nuestra [...]. En mi caso digo: bueno podría haber... no sé, haber avanzado más, intentar... en vez de ser trabajador, ser autónomo. No sé, supongo que algo habremos hecho mal (Jenaro).

Pero no sé exactamente el motivo, que soy poco emprendedor o poco ambicioso (Andrés).

Ambas son expresiones del callejón sin salida que atribuye todos los éxitos y todos los fracasos al individuo, lo que desde el punto de vista del gobierno del desempleo, es especialmente útil para despolitizar los casos de fracaso mediante la culpabilización. La creencia de quien ha incorporado la ideología del emprendedor, según la cual es la inteligencia y el esfuerzo individual lo que le dará - o le daría - la posibilidad de salvarse, se romperá con otra nueva crisis, cuando emerja la posición de dependencia objetiva de quienes compiten por el escaso trabajo. El discurso del emprendimiento se lanza desde arriba, como decíamos, en las condiciones de escasez y crisis: 
te dan, a lo mejor, tres mil euros. Pero ahora como no lo hay, es un engaño. Es que no hay consumo, ni trabajo, ni capacidad de trabajo (Precarios).

Como en todos los procesos que hemos visto, no se salvará quien más se esfuerce, sino quien acumule más condiciones para posicionarse relativamente mejor que los demás cuando irrumpa la próxima crisis. La culpa del parado que no ha sido emprendedor es la otra cara de aquellos parados que intentan subjetivar positivamente su fracaso o su despido, lo que se señala a menudo con la ideología del paro como oportunidad de reinventarse, relacionado a su vez con las transformaciones en el discurso del despido (Fernández Rodríguez y Martínez Lucio, 2014):

Estaba en una situación ideal, la asociación se echó a perder, vamos, que entró en quiebra y, y entonces yo casi me alegré, bueno, como nos ha pasado a muchas, de decir «bueno, ésta es la ocasión de reinventarse, de ver qué es lo que realmente me apetece hacer, de hacer otras cosas» (Precarias).

\section{CONCLUSIONES: LÍNEAS DE CRÍTICA DEL DISCURSO DEL EMPRENDIMIENTO}

Después de este análisis puede afirmarse con más apoyo empírico que, en rigor, el emprendimiento no es una solución sustancial al desempleo, pues tal como venimos sosteniendo, ninguna solución en términos individuales puede serlo. El emprendimiento tiene las mismas características de dependencia del dinero que cualquier otra forma de relación salarial, y al igual que hay puestos de trabajador asalariado mejores y peores, no es necesariamente menos dependiente quien es reconocido como "autónomo" o emprendedor. La categoría de emprendimiento, más bien, ha de comprenderse como parte de un dispositivo de subjetivación individualizada de la relación salarial que tiende a ocultar la dependencia real, e incluso a aumentarla, ya que el trabajador tiene más dificultades para tomar conciencia de su dependencia realmente existente. La trampa consiste en que el proceso de individualización de la relación salarial produce un incremento de la dependencia objetiva que se presenta como un incremento de la independencia subjetiva. Una de las paradojas centrales es que este incremento de la independencia percibida solo se puede expandir bajo las condiciones de la significativa coacción que ha implicado la crisis:

Este autogobiemo de sí no se consigue espontáneamente como un simple efecto de un discurso empresarial seductor, que manipule la aspiración de cada cual a la autonomía. 
Este control de la subjetividad solo se produce eficazmente en el marco de un mercado de trabajo flexible donde la amenaza del desempleo es el horizonte de todo asalariado (Laval y Dardot, 2010: 231).

Efectivamente, las condiciones sociales de expansión de este discurso y de sus prácticas descansan sobre la progresiva destrucción de los soportes sociales que presionan crecientemente a las capas más vulnerabilizadas. En condiciones de escasez radical de empleos y salarios suficientes, el emprendimiento propone soluciones imposibles que, al mismo tiempo, se presentan como la única solución: se trata de una contradicción irresoluble, que en términos de discurso se presenta como un doble vínculo (Fernández Rodríguez, 2007:333). El emprendimiento promete la autonomía y libertad siempre que se eliminen las condiciones de la autonomía y la libertad; o lo que es lo mismo, promete el desarrollo de la individualidad mediante la eliminación de cualquier tiempo autónomo y libre por el imperativo de dedicación al "proyecto personal» las 24 horas al día y los 7 días a la semana (Crary, 2013). En sus fundamentos últimos, el discurso del emprendimiento trata de actualizar nuevamente la eficacia simbólica del oxímoron básico del liberalismo: que cuanto más egoísta sea cada uno individualmente, mayores serán los beneficios para el conjunto social; en fin, se trata de presentar como compatible la incompatibilidad fundamental entre la posibilidad de tener una buena vida y la intensificación generalizada de la competencia a todas las esferas de la vida. El narcisismo competitivo de la figura del emprendedor es una condición más que aumenta la dedicación del tiempo de vida al trabajo y deja sin cuestionar la división polarizada de los tiempos sociales que está en el origen de la producción capitalista de desempleo en particular, y de poblaciones superfluas en general (Briales, 2016).

Por todo lo dicho, el emprendeudamiento no genera empleo, sino que intensifica la presión de todos contra todos en la competencia por el escaso trabajo, al orientar el tiempo no remunerado del paro en un sentido de racionalización productivista del conjunto de los tiempos sociales. El dogma productivista, íntimamente asociado a los incuestionados supuestos del discurso del emprendimiento, no apunta en modo alguno hacia un aprovechamiento social de los beneficios de tal productividad, como cabría esperar. El discurso del emprendimiento difunde más aún el dogma del trabajar por trabajar y se enfrenta con la ética del trabajar para vivir, oscurece las relaciones de subordinación de la relación salarial, y estimula un falso ideal de autosuficiencia en los trabajadores. Tanto si se está en el selecto grupo de los exitosos emprendeudores como si se está en el masi- 
vo grupo de los fracasados, la solución emprendedora al desempleo no es una solución real para la mayoría de desempleados sino que, por el contrario, contribuye en un nivel socialmente general a profundizar la competitividad y el endeudamiento generalizados que hace más vulnerables a los parados en particular y a la población trabajadora en general.

\section{BIBLIOGRAFÍA}

Alonso, L. y Fernández Rodríguez, C. J. (2013): «Debemos aplacar a los mercados: el espacio del sacrificio en la crisis financiera actual», Vínculos de Historia, 2, pp. 97-119.

Alonso, L. y Fernández Rodríguez, C. J. (eds.) (2012): La financiarización de las relaciones salariales, Madrid, La Catarata.

Álvarez, N., Idoate, E., Ramírez, A. y Recio, A. (2014): Qué hacemos con el paro, Madrid, Akal.

Berardi, F. (2003): La fábrica de la infelicidad. Nuevas formas de trabajo $y$ movimiento global, Madrid, Traficantes de Sueños.

BilbaO, A. (1997): El accidente de trabajo: entre lo negativo y lo irreformable, Madrid, Siglo xxI.

Bourdieu, P. (1989): «La ilusión biográfica», Acta sociológica, 56, pp. 121-128. Briales, Á. (2016): El tiempo superfluo: una sociología crítica del desempleo. El caso de España (2007-2013), Tesis doctoral inédita, Universidad Complutense de Madrid. Disponible en: https://ucm.academia.edu/ AlvaroBriales [Consultado el 6 de diciembre de 2016]

Briales, Á. y López Calle, P. (2015): «El paro productivo. La crisis como producción de desempleo para la reactivación de la rentabilidad empresarial», Revista de Economía Crítica, 20, pp. 86-101.

BSE [BARómetro Social de EspaÑa] (2014a): «¿̨Saliendo de la crisis?: los salarios más bajos y desiguales de la serie histórica». Disponible en: www. barometrosocial.es [Consultado el 6 de diciembre de 2016]

BSE [Barómetro Social de España] (2014b): «¿Qué pasa con los salarios?» Disponible en: www.barometrosocial.es [Consultado el 6 de diciembre de 2016]

Callejo, J. (2015): «El tiempo libre ente el trabajo y los cuidados», en Prieto, C. (2015): Trabajo, cuidados, tiempo libre y relaciones de género en la sociedad española, Madrid, CINCA. 
Crary, J. (2013): 24/7: Late Capitalism and the Ends of Sleep, New York, Verso.

Crespo, E., Revilla, J. y Serrano, A. (2009): «Del gobierno del trabajo al gobierno de las voluntades: el caso de la activación», Psicoperspectivas.cl, VIII(2), pp. 82-101.

Mejide, R. (2015): «Je demande», El Periódico de Cataluña, 26/07/15. Disponible en: http://www.elperiodico.com/es/noticias/opinion/demande4386050 [Consultado el 6 de diciembre de 2016]

FERNÁNDEZ Rodríguez, C. J. (2007): El discurso del management: tiempo y narración, Madrid, CIs.

Fernández Rodríguez, C. J. y Martínez Lucio, M. (2014): «El discurso del despido libre en España: una reflexión sobre el papel de los mitos y los prejuicios en las políticas de empleo españolas», Cuadernos de Relaciones Laborales, 32(1), pp. 191-219.

FERnández Rodríguez, C. y SERrano Pascual, A. (coords.) (2014): El paradigma de la flexiguridad en las políticas de empleo españolas: un análisis cualitativo, Madrid, CIs.

Gem [Global Entrepreneurship Monitor] (2015): An Introduction to gem (Spanish). Disponible en: http://www.gem-spain.com/ [Consultado el 6 de diciembre de 2016]

- (2016): Informe España 2015. Disponible en: http://www.gem-spain. com/ [Consultado el 6 de diciembre de 2016]

LAVAL, C. y DARDOT, P. (2010): La nueva razón del mundo, Barcelona, Gedisa.

LeY 20/2007, de 11 de julio, del Estatuto del trabajo autónomo. Disponible en: https://www.boe.es/buscar/PDF/2007/BOE-A-2007-13409-consolidado.pDF [Consultado el 6 de diciembre de 2016]

Ley Orgánica 8/2013, de 9 de diciembre, para la mejora de la calidad educativa. Disponible en: https://www.boe.es/boe/dias/2013/12/10/PDFs/ BOE-A-2013-12886.PDF [Consultado el 6 de diciembre de 2016]

LEY 14/2013, de 27 de septiembre, de apoyo a los emprendedores y su internacionalización. Disponible en: https://www.boe.es/boe/ dias/2013/09/28/PDFs/BOE-A-2013-10074.PDF [Consultado el 6 de diciembre de 2016]

López Carrasco, C. (2015): «La materialitat del treball immaterial: algunes claus per a una aproximació alternativa al treball en el capitalisme tardà», Revista Catalana de Sociologia, 30, pp. 5-18.

MARX, K. (1857): Elementos fundamentales para la crítica de la economía política (Grundrisse), Madrid, Siglo xxI, 1971 (3 volúmenes).

Moruno, J. (2015): La fábrica del emprendedor, Madrid, Akal. 
Negueruela, E. (2014): Tasa de Protección por paro según Comunidad Autónoma, sexo y edad (EPA $1^{\text {er }}$ trim. 2014), Madrid, Fundación Primero de Mayo.

Observatorio Metropolttano (2010): Fin de ciclo: financiarización, territorio y sociedad de propietarios en la onda larga del capitalismo bispano (1959-2010), Madrid,Traficantes de sueños.

- (2011): La crisis que viene, Madrid, Traficantes de sueños.

- (2012): Spanish neocon. La revuelta neoconservadora en la derecha española, Madrid,Traficantes de sueños.

Pérez Orozco, A. (2014): Subversión feminista de la economía. Aportes para un debate sobre el conflicto capital-vida, Madrid, Traficantes de Sueños.

Prieto, C. (coord.) (2015): Trabajo, cuidados, tiempo libre y relaciones de género en la sociedad española, Madrid, cinCA.

Rolle, P. (2003): «Por un análisis ampliado de la relación salarial», Cuadernos de Relaciones Laborales, 21 (2), pp. 145-175.

SANTIAGO, J. (2015): «Individualización, vida cotidiana y redefinición de las relaciones de género», en Prieto, C. (2015): Trabajo, cuidados, tiempo libre y relaciones de género en la sociedad española, Madrid, CINCA.

SENNET, R. (1998): La corrosión del carácter, Barcelona, Anagrama.

Vозко, L. (2010): Managing the margins. Gender, Citizenship and the International Regulation of Precarious Employment, New York, Oxford University Press.

WALTERS, W. (2000): Unemployment and government: Genealogies of the social, Cambridge, Cambridge University Press. 
Anexo metodológico

perfiles de los grupos de discusión y entrevistas

\begin{tabular}{|c|c|c|c|c|c|c|}
\hline $\begin{array}{l}\text { Grupos de } \\
\text { discusión y } \\
\text { entrevistas }\end{array}$ & GÉNERO & $\begin{array}{c}\text { TIEMPO } \\
\text { EN PARO }\end{array}$ & CLASE & HOGAR & EDAD & $\begin{array}{l}\text { CIU- } \\
\text { DAD }\end{array}$ \\
\hline $\begin{array}{l}\text { Parados corta } \\
\text { duración } \\
\text { (Parados CD) }\end{array}$ & Hombres & 6-12 meses & $\begin{array}{l}\text { Populares } \\
\text { Medias }\end{array}$ & $\begin{array}{c}\text { Con pareja } \\
\text { e hijos }\end{array}$ & $\begin{array}{c}30-45 \\
\text { años }\end{array}$ & Cádiz \\
\hline Precarios & Hombres & Intermitente & $\begin{array}{l}\text { Populares } \\
\text { Medias }\end{array}$ & $\begin{array}{l}\text { La mitad } \\
\text { con hijos }\end{array}$ & $\begin{array}{c}30-45 \\
\text { años }\end{array}$ & Madrid \\
\hline Precarias & Mujeres & Intermitente & $\begin{array}{l}\text { Populares } \\
\text { Medias }\end{array}$ & $\begin{array}{l}\text { Todas con } \\
\text { pareja e } \\
\text { hijos }\end{array}$ & $\begin{array}{c}30-45 \\
\text { años }\end{array}$ & Cádiz \\
\hline Andrés & Hombre & $\begin{array}{l}\text { Más de } 4 \\
\text { años }\end{array}$ & Medias & $\begin{array}{l}\text { Madre } \\
\text { mayor }\end{array}$ & $40-49$ & Madrid \\
\hline Antonio & Hombre & 2-4 años & Populares & $\begin{array}{l}\text { Pareja + Hijo } \\
\quad+\text { Familiar }\end{array}$ & $30-39$ & Madrid \\
\hline Daniel & Hombre & 1-2 años & Medias & Pareja & $30-39$ & Madrid \\
\hline Hilario & Hombre & 1-2 años & Populares & Solo/a & $50-60$ & Madrid \\
\hline Jenaro & Hombre & 1-2 años & Populares & $\begin{array}{l}\text { Pareja + } \\
\text { hijos/as }\end{array}$ & $40-49$ & Madrid \\
\hline José & Hombre & 2-4 años & Populares & $\begin{array}{c}\text { Familia de } \\
\text { origen }\end{array}$ & $30-39$ & Madrid \\
\hline Matilde & Mujer & 6-12 meses & Populares & Hijos/as & $50-60$ & Madrid \\
\hline
\end{tabular}

